\title{
MAPS AND GRAPHS
}

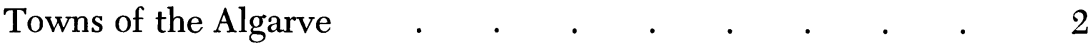

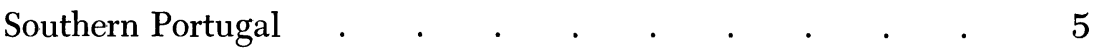

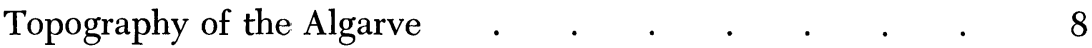

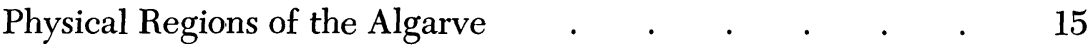

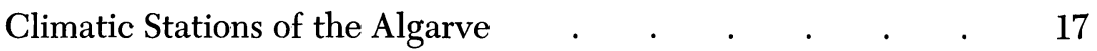

Agricultural Calendar of the Sotavento: Important Irrigated

Crops . . . . . . . . . . . . 63

Agricultural Calendar of the Sotavento: Important Unirrigated

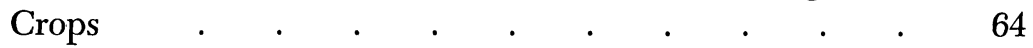

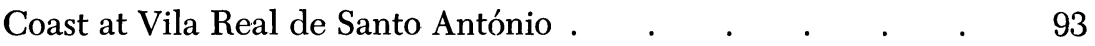

Coast at Portimão-Lagos .

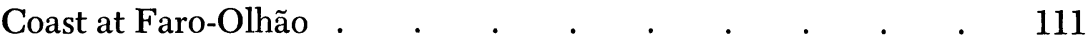

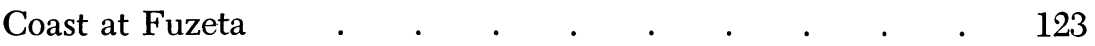

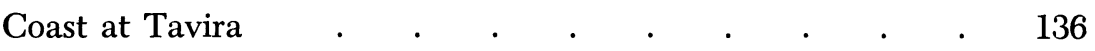

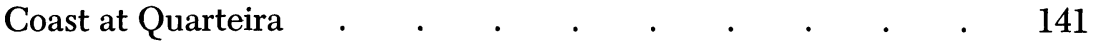

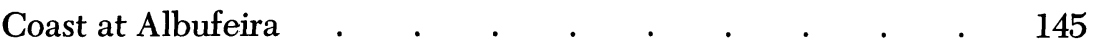

Coast at Armação de Pera $\quad . \quad$. $\quad . \quad$. $\quad . \quad$. 148

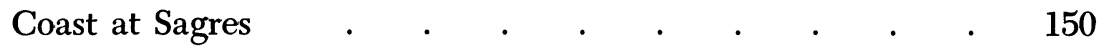

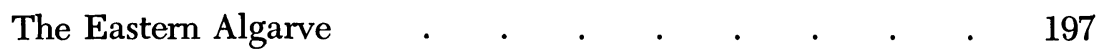

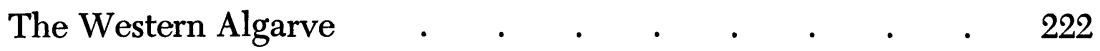
xiv 